\title{
Mecanismos de privatização na/da educação brasileira: a escola pública, gratuita e laica em risco
}

\author{
Ana Lúcia Santos Souza \\ Daisi Teresinha Chapani
}

\section{Resumo}

Este artigo tem como objetivo analisar os principais mecanismos de privatização na/da educação brasileira, com ênfase nas políticas educacionais empreendidas nos últimos anos, contexto marcado por grandes mudanças no papel do Estado, principalmente no que diz respeito à crescente negligência com as questões sociais e a adoção de ações em defesa do mercado. O texto apresenta uma discussão a respeito das sutis estratégias de privatização na educação, em concordância e parceria com o Estado, o qual opera ao mesmo tempo, como agente agregador dos atores que constroem as bases privatistas e como financiador dos mesmos. O estudo evidenciou que os mecanismos atuais de privatização da educação podem concorrer para o aprofundamento da crise de qualidade no ensino, em especial na educação básica, que tem sido o alvo principal das reformas privatizantes, em sua maioria, ambíguas. Consideramos que é preciso estabelecer vias de enfrentamento pelos grupos de base, em busca de novas alternativas que deem suporte para a garantia da educação pública, gratuita, laica e de qualidade.

Palavras-chave: Políticas públicas; Estado; Privatização; Democracia. 


\title{
Mechanisms of privatization on/of brazilian education: public, free and secular school in danger
}

\author{
Ana Lúcia Santos Souza \\ Daisi Teresinha Chapani
}

\begin{abstract}
This article aims to analyze the main mechanisms of privatization in/of Brazilian education, with emphasis on the educational policies undertaken in recent years, a context marked by major changes in the role of the State, especially in regard to increasing neglect of social issues and adoption of actions in defense of the market. Our text presents a discussion on the subtle strategies of privatization in education, in agreement and partnership with the State, which operates at the same time, as an aggregating agent of the actors who construct the privatist bases and as their main financier, through partnerships. The study showed that the current mechanisms of the privatization of education may contribute to the deepening of the crisis of quality in education, especially in basic education, which has been the main target of the privatization reforms, most of them ambiguous. We believe that it is necessary to establish ways of coping with this situation by base groups, in search of new alternatives that support the guarantee of free, laic and quality public education.
\end{abstract}

Keywords: Public policies; State; Privatization; Democracy. 


\section{Introdução}

"Compre uma empresa pública, um banco, uma ferrovia, uma rodovia, um porto. $\mathrm{O}$ governo vende baratíssimo. Ou pode até doar” (BIONDI, 1999, p. 5). Com essas palavras, Aloysio Biondi iniciou seu livro intitulado: O Brasil Privatizado, lançado em 1999.

As discussões a respeito das privatizações, intensificadas a partir do final do século passado, podem nos levar a pensar que esse fenômeno restringe-se à venda de ativos públicos. Nesse sentido, caberiam questionamentos sobre se, de fato, estaríamos vivenciando um amplo processo de privatização da educação brasileira. Mas, existem diferentes formas de privatização e, sendo a educação um tema sensível nas políticas sociais, as utilizadas nesse campo são bastante sutis, algumas quase imperceptíveis.

Assim, o objetivo desse trabalho é discutir alguns dos mecanismos que vem sendo utilizados para privatizar a educação no Brasil. Partimos de uma perspectiva histórica, mas nosso foco é o momento presente, pois estamos observando inícios de graves perigos para a educação pública, gratuita e laica.

O texto está dividido em três tópicos. No primeiro, apresentamos algumas definições e tipologias de privatização. No segundo, tratamos da relação entre o público e o privado na história da educação brasileira. No terceiro, damos alguns exemplos de mecanismos de privatização em curso nesse momento em nosso país.

\section{Privatização: conceitos, tipos e formas}

A partir da década de 1970 começou a se desmanchar uma forma de organização social que, nos países capitalistas, buscava o equilíbrio entre legitimação democrática e a acumulação do capital, resguardando os cidadãos com uma série de direitos sociais, constituindo-se no Estado de Bem Estar Social. De acordo com Moraes (2004), o desmantelamento dessa estrutura sobreveio quando o capital transnacional começou a opor-se às regulações nacionais, encontrando maneiras de contorná-las e, finalmente, desfechou ataques contra à legislação trabalhista e apelou para a privatização, para a desregulamentação dos sistemas financeiros e para a liberalização comercial, alfandegária e ambiental. De modo que, antes mesmo do final do século XX, já se podiam notar os resultados dessas alterações na redução das políticas sociais, nas mudanças nas relações de trabalho e nas novas configurações ideológicas.

Nesse contexto, organismos internacionais e forças internas têm exercido pressões para que os governos se desresponsabilizem de áreas como: saúde, previdência, direitos trabalhistas, cultura e educação (MOARES, 2004; VIEIRA at al., 2018). A instauração de um Estado Mínimo (em direitos sociais), que se corporifica como um Estado Máximo (em controle geral), tem sido posta como a única alternativa viável ao agonizante Estado de Bem Estar Social. No Brasil, temos assistido desde o final da década de 1990, a concretização de tais 
ideais, ora explicitamente ora de maneira fortuita, nas políticas educacionais (CHAPANI, 2014; LIBÂNEO, 2016).

Nesse cenário, a privatização educacional faz parte das agendas globais e tem sido discutida de maneira crescente por diversos estudiosos ao redor do mundo. Ball e Youdell (2007), afirmam que:

la privatización en la educación pública y de la educación pública tiene sus raíces en los diversos enfoques de "pequeño Estado - libre mercado" aplicados a los servicios públicos (lo que algunas veces se denomina el "neoliberalismo") que se han manifestado expresamente en muchos contextos nacionales desde los pasados años ochenta y que ahora se han extendido por todo el mundo (p. 12).

Conforme Ball e Youdell (2007), a privatização pode acontecer de duas maneiras: a privatização na educação pública ou privatização endógena, caracterizada pela inserção da lógica do setor privado no setor público; e a privatização da educação pública ou privatização exógena, que implica na participação do setor privado no setor público. Os autores enfatizam que,

la primera forma de privatización, según la cual se pide al sector público que se comporte cada vez más como el sector privado, está muy extendida y bastante bien consolidada. La segunda forma de privatización, según la cual el sector privado se introduce en la educación pública, es una vía más reciente de privatización que crece a gran velocidad. Ambas formas de privatización no se excluyen mutuamente, sino que muy a menudo están interrelacionadas, ya que de hecho la privatización exógena muchas veces es posible gracias a modalidades endógenas previas. (BALL; YOUDELL, 2007, p. 13).

No Brasil, temos visto essas duas formas de privatização, pois a lógica de mercado, baseada na competitividade, eficácia, eficiência e regulação, está cada vez mais presente no cenário educacional; além disso, também temos a ampliação do setor privado na educação brasileira. Lima (2013) observa que a privatização assume diversas características e pode se materializar sob muitas e diferentes perspectivas, tais como: desmonte da responsabilização estatal para beneficiar a iniciativa privada, falta de regulação, concessão de serviços a entes privados, parcerias público-privadas, criação de redes de ensino híbridas, escolas públicas com gestão privada, financiamentos por meio de bolsas de estudos ou de cheques-ensino, interferência privada no currículo, ação do terceiro setor. Para o autor,

Privatização pode, ainda, significar a crescente introdução de modos de gestão considerados típicos das organizações privadas, ideologicamente consideradas mais bem geridas, em busca da "zero-burocracia", mais ágeis e manejáveis em ambientes incertos e turbulentos, centradas nas necessidades do cliente ou consumidor, induzindo a competitividade no seu interior através da adoção de mercados internos, ou seja, seguindo os princípios normativos e 
as prescrições técnico-instrumentais da chamada "Nova Gestão Pública", que tenho associado ao que designo por "cânone gerencialista" (LIMA, 2013, p. 178-179).

Segundo Belfield e Levin (2004, p. 17), a privatização pode ser definida como "uma liberalização - quando os agentes são libertados das regulações governamentais - e uma mercantilização - quando são criados novos mercados que proporcionam alternativas aos serviços do governo ou aos sistemas de distribuição estatal". Ainda de acordo com os autores, a privatização apresenta-se de três formas: oferta privada (quando a educação é ofertada pela iniciativa privada - grupos religiosos, empresas e associações - sem nenhuma dependência dos setores governamentais); financiamento privado (educação financiada/paga pelos pais, sem apoio do governo); regulação, gestão e monitorização privadas (gestão e regulação pública, com monitoramento de qualidade tanto pelo ente governamental, tanto pelas famílias e alunos).

Belfield e Levin (2004) apresentam variados programas e políticas de privatização: cheques-ensino (é concedido um valor anual ao aluno para a família destinar à uma escola privada conveniada); desregulamentação da escola pública (redução da burocracia, para que sejam mais eficientes e respondam às mudanças); contratação de serviços específicos (transporte, alimentação, serviços de limpeza, pacotes instrucionais, etc.); benefícios e isenções fiscais às famílias (dedução em imposto do indivíduo); subsídios e bolsas à escolas privadas (concessão de bolsas a instituições privadas, favorecendo a procura); ensino doméstico e pagamentos privados de educação (afastamento das famílias em relação ao sistema oficial de ensino, para oferta de ensino domiciliar; já os pagamentos privados podem ser em forma de aulas extras, como reforço escolar); competição entre escolas ou instituições educativas (incentivo à busca da competitividade por maior qualidade entre as escolas). Esses programas e políticas de privatização são desenvolvidos em diversos países do mundo, conforme as particularidades de cada um. No Brasil, por exemplo, percebemos a adoção de várias dessas ações, conforme exemplificaremos no tópico 3.

\section{Público e privado na história da educação brasileira}

A despeito dos múltiplos significados que os termos público e privado possam carregar, nossa delimitação está restrita ao regime jurídico das instituições envolvidas (MELLO, 1975 apud DOURADO; BUENO, 2001) e à origem dos recursos financeiros que as sustentam.

Ao empreender uma digressão sobre o processo de evolução da educação brasileira, Cury (2005) mostra que no período colonial, a formação da sociedade brasileira sofreu influências do modelo estatal português e da igreja Católica. O autor observa que, em tempos

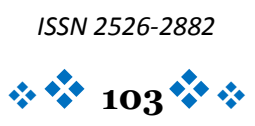


históricos diferentes, a educação esteve sob submissão de “quatro senhores”: Estado, família, iniciativa privada e Igreja.

Após a expulsão dos jesuítas, o Estado instituiu as Aulas Régias ou Aulas Públicas, cobrando um imposto para a sua manutenção. No entanto, "em determinadas ocasiões, a Coroa chegou mesmo a delegar aos pais a responsabilidade pelo pagamento dos mestres, o que mostra como a educação, tornada pública pela lei, esteve, em grande parte, circunscrita ao âmbito da vida familiar" (XAVIER, 2003, p. 256).

Segundo Xavier (2003, p. 239), foi no Período Imperial que se afirmou o valor social da educação escolar atribuindo-lhe um sentido "aproximado do que se entende, hoje, como educação pública-estatal”, a partir do "controle do Estado sobre a educação do povo". Também a partir desse período, ideias liberais recém incorporadas ao país, fomentaram a difusão da educação por meio abertura de classes, tanto por leigos quanto por religiosos. Para Akkari et al. (2011, p. 476), inicia-se aí o modelo duplo da educação brasileira, ficando "a iniciativa privada responsável pelo ensino da elite e o Estado, pela educação dos filhos dos trabalhadores".

Mesmo na Primeira República não havia perspectivas reais de construção de um sistema público de ensino, pois, de um lado estava a elite, detentora das terras e de poder político, com direito à instrução e de outro, ex-escravos, pobres, comerciantes, mestiços etc. com acesso à educação, mesmo a mais elementar, comprometido devido às condições objetivas (XAVIER, 2003).

Nas primeiras décadas do século XX, com o desenvolvimento da industrialização, fortaleceu-se a preocupação em se educar o trabalhador urbano, o que demandou a abertura de escolas e a implementação de reformas educacionais. Intensificou-se também o investimento estatal em níveis mais elevados da educação, invertendo-se a lógica da educação elementar: quem tem acesso ao ensino superior público são as elites. Segundo Dourado e Bueno (2001, p. 53):

O conflito público/privado vai margear os desdobramentos do Estado no Brasil e as implicações disso na órbita de suas políticas. Na área educacional, esse atrito, plenamente configurado a partir dos anos 30 [do século XX], vai desenhar-se como resultante das disputas político-ideológicas por hegemonia entre os defensores da escola pública e os defensores da escola privada, nas décadas seguintes, e vai ser objeto de vários estudos e pesquisas que tentam compreender como se processa a interpenetração dessas esferas.

Nessa época, as discussões no campo educacional foram marcadas por uma visão liberal. Destaca-se, nesse contexto, o Movimento dos Pioneiros da Educação Nova, composto por intelectuais e educadores que defendiam a educação pública, gratuita e de qualidade, livre de influências político-partidárias e religiosas. Embora a Constituição de 1891 adotasse o

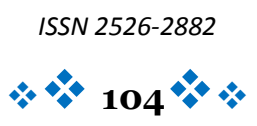


princípio da laicidade, a Igreja Católica lutava por espaço, por defender que a educação moral do povo era de sua responsabilidade.

Assim, as políticas educacionais dos anos 30 buscavam atender às reivindicações dos intelectuais e educadores e também dos industriários, dos empresários e da Igreja. A Constituição de 1934 assegurou, por um lado, o ensino primário obrigatório, gratuito e universal e por outro, o ensino religioso nas escolas, o reconhecimento de estabelecimentos particulares e do papel desempenhado pela família na educação, bem como a isenção de impostos das instituições privadas de ensino (SHIROMA; MORAES; EVANGELISTA, 2002).

No Estado Novo, o dualismo educacional se acentuou, pois enquanto as elites tinham acesso à educação superior, restava aos pobres o ensino basilar e profissional. As reformas educacionais dos anos 40, estreitaram a relação entre Estado e iniciativa privada. Em um contexto de notável industrialização, foram criados o Serviço Nacional de Aprendizagem Industrial (SENAI) e o Serviço Nacional de Aprendizagem Comercial (SENAC), organizações privadas, com imunidade tributária e recursos oriundos de contribuição compulsória, responsáveis pela educação industrial e comercial, respectivamente. Atualmente essas instituições atuam em ampla frente no setor educacional, da pré-escola à pós-graduação ${ }^{21}$.

A Constituição de 1946 prescrevia a educação como direito de todos, no entanto, era notável a forte intervenção da iniciativa privada, a ponto de durarem 13 anos as discussões para a aprovação da Lei de Diretrizes e Bases da Educação Nacional (Lei 4024/61), qual resultou "na vitória das forças conservadoras e privatistas e sérios prejuízos quanto à distribuição de recursos públicos e à ampliação das oportunidades educacionais" (SHIROMA; MORAES; EVANGELISTA, 2002, p. 29), pois a referida lei assegurava ajuda financeira para a rede privada e às instituições vocacionais.

Segundo Cunha (2001), o período pós 1946 corresponde à primeira experiência democrática brasileira, ainda que limitada por práticas populistas. Mas foi um interstício breve, pois em 1964 ocorreu o golpe militar.

Durante os governos militares, a educação foi fortemente marcada pela teoria do capital humano. Por meio da lei 5.540/68, o Estado reformou o Ensino Superior e pela lei $5692 / 71$, o ensino de $1^{\circ}$ e $2^{\circ}$ graus (correspondentes aos ensinos fundamental e médio). Nesse contexto,

Os partidários da escola pública estavam desarticulados ou haviam sido cooptados pera reforma e os interesses privados foram plenamente atendidos. A nova lei [5692/71] assegurava espaço para o ensino religioso e ampliava o princípio privatizante garantindo amparo técnico e financeiro à iniciativa privada (SHIROMA; MORAES; EVANGELISTA, 2002, p. 38).

${ }^{21}$ http://www.portaldaindustria.com.br/senai/ e http://www.dn.senac.br/ ISSN 2526-2882

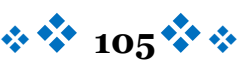


Ao mesmo tempo em que o Estado ampliou a obrigatoriedade de ensino para oito anos, excluindo os exames admissionais para o ginásio, não buscou meios efetivos para garantir a estrutura escolar e a qualidade do ensino para toda a população. $O$ fortalecimento do ensino profissionalizante, no $2^{\circ}$ grau, intentava apenas uma formação básica para ingresso no mercado de trabalho, uma manobra para evitar que as massas pleiteassem a educação superior, que se expandia sob o comando da iniciativa privada. Shiroma, Moraes e Evangelista (2002) ressaltam que a indiferença do Estado ante às reais necessidades educacionais, principalmente no que tange ao financiamento da educação pública e gratuita, deram margem para que a educação se tornasse uma via promissora de lucro. As afinidades político-ideológica entre o poder instituído e a iniciativa privada promoveu o encorajamento desta durante o regime militar. Porém, mesmo pós a redemocratização, o setor privado "não sofreu qualquer prejuízo, ao contrário, foi reforçado” (AKKARI et al, 2011, p. 483).

O tsunami neoliberal, que repercutiu globalmente a partir da década de 1980, desencadeou várias reformas normativas e estruturais, de modo que o aparato jurídico do campo educacional (desde a Constituição Federal de 1988, passando pela Lei de Diretrizes e Bases - 9394/96 - até as normas delas derivadas) foi impregnado pelos interesses do mercado. As reformas empreendidas nessa época, ecoam ainda hoje, dadas as constantes e diferentes manobras de privatização da/na educação pública.

No que concerne às opacas relações entre o público e o privado, chamamos a atenção para a aprovação, durante o governo de Fernando Henrique Cardoso (FHC), em 1999, do Fundo de Financiamento ao Estudante de Ensino Superior (Fies), que substituiu o antigo Crédito Educativo. Trata-se de um financiamento, com juros subsidiados, feito para alunos de baixa renda que estudam em Instituições de Ensino Superior (IES) privadas (ROSA, 2013).

Durante os governos do PT (2013-2016), embora a lógica mercantil não tenha deixado de fundamentar as políticas educacionais, o Estado comprometeu-se com a expansão da educação pública em todos os níveis e com a inclusão de grupos historicamente deixados à margem da educação, principalmente com relação aos níveis mais elevados. Alguns programas desenvolvidos nesse período estiveram voltados ao fortalecimento da educação pública, como o (Programa de Apoio ao Plano de Reestruturação e Expansão das Universidades Federais Reuni- e a Expansão da Rede Federal de Educação Profissional, Científica e Tecnológica), porém, outros apresentaram um caráter ambíguo no que diz respeito à relação público/privado (como o Programa Universidade para Todos - Prouni) (ROSA, 2013).

Com o afastamento de Dilma Rousseff e a assunção de Michel Temer em 2016, as perspectivas privatistas endureceram, sendo que "uma de suas primeiras medidas foi retornar à implementação, com intensidade, das reformas preconizadas pelo Consenso de Washington. 
Recomeçaram as privatizações, a abertura do mercado às empresas estrangeiras, as reformas da previdência e trabalhista etc.” (AMARAL, 2017, p. 06).

O chamado Consenso de Washington refere-se a uma série de diretrizes de austeridade fiscal formulada por economistas de instituições financeiras, a partir de uma reunião ocorrida em Washington, capital dos Estados Unidos, em 1989, as quais se converteram em políticas do Fundo Monetário Internacional (FMI), que passou a impô-las aos países tomadores de empréstimos. Tais diretrizes referem-se a:

(1) disciplina fiscal; (2) priorização dos gastos públicos; (3) reforma tributária; (4) liberalização financeira; (5) regime cambial; (6) liberalização comercial; (7) investimento direto estrangeiro; (8) privatização; (9) desregulação; e (10) propriedade intelectual" (BATISTA, 1999, apud AMARAL, 2017, p. 03).

Os organismos internacionais preconizaram que a disciplina fiscal deveria ser efetivada, dentre outros meios, pela redução ou corte dos gastos públicos e privatização das estatais e serviços públicos. No Brasil, a aprovação da Emenda Constitucional 95/2016, a PEC do teto dos gastos, é um caso emblemático de atendimento às pressões em favor da contenção de recursos públicos para políticas sociais.

No que tange às implicações da referida emenda sobre a educação básica, afirmamos que são drásticas, uma vez que instituiu um Novo Regime Fiscal (NRF) por 20 anos (20162036), que afetará violentamente os processos e resultados educacionais nos estados e municípios. Não é preciso ter habilidades de previsão do futuro para perceber que há implicações sérias, no que tange aos investimentos em estrutura escolar e ampliação das redes de ensino, aquisição de materiais pedagógicos, inovações pedagógicas, admissão de profissionais (via concursos públicos), dentre outros. Soma-se a isso, o comprometimento do Plano Nacional de Educação (2014-2024), pois não será possível cumprir suas muitas de suas metas, já que isso requer ampliação de investimentos em recursos (AMARAL, 2017).

Ao empreender uma análise fiscal das implicações da EC 95/2016 sobre o financiamento da educação pública, Bassi (2018) observa que há um estreitamento de compartilhamento de custos entre a União, estados e municípios. O problema posto aqui é: a arrecadação líquida desses entes federados tem se reduzido nos últimos anos, sendo um dos motivos, a redução dos repasses pelo governo federal. Por isso, analisamos, grosso modo, que a EC 95/2016 é mais um dispositivo fiscal que implica em desresponsabilização estatal, de privatização, de precarização da educação, da formação e trabalho docente. Os rumos da educação básica até 2036 são incertos, no entanto, restam expectativas e esperanças, pois o tempo é dinâmico e a realidade é forjada pelas lutas históricas. 
Desse modo, avançamos no século XXI reagindo às intensas tentativas de submeter a educação, de forma mais abruta, aos interesses mais fortuitos do mercado. Segundo Apple (2003, p. 41),

entramos num período de reação ao ensino. Nossas instituições educacionais são vistas como fracassos completos. Índices elevados de desistência, declínio da "alfabetização funcional", queda no padrão de qualidade e na disciplina, dificuldade de transmitir o "verdadeiro saber" e de profissionalizar os alunos, notas baixas nas provas padronizadas etc. - todas essas acusações feitas contra as escolas. E todas elas, dizem-nos, levaram ao declínio da produtividade econômica, ao desemprego, à pobreza, à falta de competitividade internacional e assim por diante. Retornem a uma "cultura comum", tornem as escolas mais eficientes, mais receptivas ao setor privado. Façam isso que nossos problemas serão resolvidos.

O autor observa que nos Estados Unidos o neoliberalismo se reinventou no final do século XX, lançando mão da modernização conservadora, o neoconservadorismo e o populismo autoritário, somando-se às influências da direita cristã e rica. Essa realidade repercute atualmente no Brasil a tal ponto de vermos claramente a inserção de mecanismos de controle do trabalho docente e anseios de retorno às tradições. De modo que "a desconfiança em relação aos professores, a preocupação com uma suposta perda de controle cultural e a sensação de 'poluição' perigosa estão entre os muitos temores culturais e sociais que impulsionam as políticas neoconservadoras" (APPLE, 2003, p. 63).

Contemporaneamente, o neoconservadorismo impregnado no Brasil tem sido favorável ao surgimento de novos atores concorrentes à educação pública, como por exemplo, determinadas Igrejas Evangélicas Neopentecostais, que, além de investirem progressivamente em instituições de ensino privadas, têm interferido nos rumos da educação brasileira, não apenas por meio de atuação parlamentar, mas também por influência de seus representantes nas ações executivas. Esses grupos conversadores vêm pressionando para a inclusão da educação moral e cívica e a obrigatoriedade do ensino religioso no currículo, realizando ataques à educação sexual e à discussão sobre gênero nas escolas, repelindo a liberdade de cátedra etc. Muitos desses princípios estão contidos no "Movimento Escola Sem Partido".

Chama a atenção também a intensa participação de instituições como Organizações não Governamentais (ONGs), fundações, institutos etc., que têm recebido recursos públicos para atuarem no campo educacional. Peroni e Caetano (2012) mostram que as parcerias entre o público e privado, via terceiro setor, representam uma das formas de incorporação da lógica privada nas instituições públicas. De fato, alguns dos sujeitos mais influentes na definição das políticas educacionais mais recentes são representantes do setor privado, bem como "institutos e fundações ligados a grandes empresas nacionais e internacionais, bem como instituições financeiras ligadas ao mercado de capitais, visando construir um projeto hegemônico de 
educação e de sociedade" (PERONI; CETANO; LIMA, 2017, p. 418). Assim, os principais envolvidos no processo de construção da Base Nacional Comum Curricular e do novo Ensino Médio, apresentam-se como sujeitos individuais ou coletivos por meio de instituições privadas que atuam no setor educacional.

Nas eleições de 2018, a coalização que saiu vencedora das urnas formou-se, entre outros atores, com grupos que defendem a liberalização da economia e outros, por paradoxal que possa parecer, o conservadorismo social. Ambos são motivos de preocupação para aqueles que defendem a educação pública, gratuita e laica, pois de um lado, prega-se a redução dos investimentos estatais em políticas sociais, por outro, justamente a intervenção do Estado na fixação de um currículo antenado com os princípios conservadores e autoritários.

\section{Mecanismos de privatização na/da educação: cenário atual}

Conforme indicado anteriormente, na educação a privatização não ocorre de forma explícita, com leilões de escolas e universidades públicas, mas, são usados mecanismos pouco visíveis. A principal estratégia utilizada para ocultar os processos de privatização é o borramento de fronteiras entre o público e o privado.

Segundo Dourado e Bueno (2001, p. 53), a organização atual do Estado brasileiro produz "uma situação perversa da ação estatal, na medida em que esta não estabelece as fronteiras e diferenças entre os interesses coletivos e os interesses particulares, facultando a emergência da privatização do público e, consequentemente, a interpenetração entre as esferas público e privado". Concordando com tal argumento, Akkari et al (2011, p. 482) afirmam que "a ideia de indefinição de fronteiras é apropriada e pertinente para analisar a construção das desigualdades educacionais no Brasil”, pois “essa indefinição permite diluir responsabilidades, especialmente aquelas do Estado e das elites políticas".

Nesse tópico, discutiremos alguns exemplos privatização em curso na educação brasileira, os quais, em geral, fazem uso de mecanismos sutis para obscurecer a relação público/privado.

\section{A privatização na educação: a inserção da mentalidade empresarial nas políticas educacionais}

O processo de formulação das políticas públicas se traduz em um jogo de interesses que ocorre em diferentes arenas de conflitos (STEIN et al., 2007).

Entre os jogadores que participam desse jogo, encontram-se atores estatais oficiais e políticos profissionais (presidentes, líderes de partidos, legisladores, juízes, governadores, burocratas), assim como grupos privados, sindicatos, meios de comunicação, e outros membros da sociedade civil. Esses atores interagem em diferentes arenas, que podem ser formais (como o Legislativo

ISSN 2526-2882

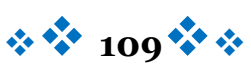


ou o ministério), ou informais ("a rua") e podem ter distintos graus de transparência (STEIN et al. 2007, p. 17).

No entanto, esses atores não se encontram em condições de igualdade, pois alguns detém mais poder que outros. Embora a formulação das políticas envolva atores de diversos segmentos sociais, atualmente no Brasil tem havido dificuldades para a ampla participação popular nos debates. Os políticos, o empresariado e grupos religiosos têm tomado as rédeas sobre o processo de formulação das políticas educacionais.

No dia 22 de setembro de 2016, com menos de um mês da posse de Michel Temer, foi encaminhada para o Congresso a Medida Provisória (MP) 746/2016, com propostas de reformas para o Ensino Médio. A urgência de formulação e de aprovação desta MP (convertida na lei 13.415/2017), repercutiu na mídia e sociedade civil, com ênfase na possibilidade de extinção de determinadas disciplinas e de exercício da docência por pessoas com "notório saber" em alguma especialidade técnico-profissional, passando despercebido outros aspectos polêmicos (FERRETI; SILVA, 2017). Vale ressaltar que essa MP já estava prenunciada desde 2015, quando iniciaram as discussões para a elaboração da Base Nacional Comum Curricular (BNCC), que concebe a formação no Ensino Médio, com base no desenvolvimento de competências e foco no individualismo.

A Base Nacional Comum Curricular teve como mola de projeção o Movimento pela Base Comum Curricular, composta por sujeitos de instituições públicas e privadas, fundações e institutos integrantes do terceiro setor, tais como: “Fundação Lemann, principal apoiadora e articuladora da reforma curricular, Cenpec, Instituto Natura, Instituto Ayrton Senna, Instituto Unibanco, Fundação SM, Insper e Instituto Fernando Henrique Cardoso” (PERONI, 2015, p.346).

Dadas as influências da iniciativa privada na formulação das políticas educacionais, esses documentos (MP 746/2016 e BNCC) mantém entre si dois elementos em comum: 1) preocupações com os resultados do PISA, tanto pelo ranqueamento das escolas estaduais, quanto pela qualidade da educação entre os países, demonstrada pelos índices e 2) foco na educação enquanto meio formativo de jovens aptos a servirem ao mercado de trabalho (trabalhadores competentes), além de consumidores e cidadãos adaptáveis ao modelo capitalista neoliberal (FERRETI; SILVA, 2017).

Não por acaso, o empresariado tem aumentado seu interesse pelas questões educacionais que afetam o país no que tange à educação básica e, particularmente, ao ensino médio, desde que se avolumaram as informações e análises relativas às novas demandas de perfil do trabalhador decorrentes dos processos de reconfiguração do capitalismo a partir da década de 1970, os quais afetaram as tecnologias e a gestão da produção. Tal tipo de interesse manifestou-se, tanto no período do governo FHC [Fernando Henrique Cardoso] quanto no dos governos Lula e Dilma, pela disposição e pelo 
empenho em interferir de forma decisiva no âmbito do ensino médio, contando, para isso, com o apoio não apenas da mídia, mas também de setores do campo acadêmico, como, por exemplo, o econômico (FERRETI; SILVA, 2017, p. 398).

Nesse sentido, a aprovação da Lei de Reforma do Ensino Médio (Lei no 13.415/2017) foi uma ação resultante de jogos de interesse das elites dominantes em seus esforços de implementar uma proposta de educação para o Ensino Médio, balizada nos ideais do mercado, mas que, além disso, fornecesse vias de captação dos recursos públicos. Isso está visível no corpo da lei, ao instituir que os sistemas de ensino poderão firmar convênios com instituições de ensino a distância (EaD) para complemento da carga horária curricular (BRASIL, 2017). As novas Diretrizes Curriculares Nacionais para o Ensino Médio, homologadas pelo MEC no dia 20 de novembro de 2018 estabelecem que os sistemas de ensino poderão ofertar o ensino com complementação EaD, em até 20\% para o diurno, 30\% para o noturno e 80\% para a EJA. Ou seja, está aberta uma porta para que boa parte da educação básica seja feita por instituições privadas.

Após um mês e meio da aprovação que reforma o Ensino Médio, o congresso aprovou, também de forma célere, a lei $n^{0}$ 13.429/2017, que regula a contratação de serviços terceirizados, aprofundando ainda mais a precarização do trabalho. Além dos graves impactos trazidos por essa lei nas relações de trabalho, ela engrossa o pacote de medidas de desresponsabilização estatal e de privatização dos serviços públicos, pois abre caminhos para o alargamento da contratação de profissionais da educação, via parceria com empresas privadas, incluindo professores e gestores, o que, por conseguinte, aprofunda a precarização e desvalorização do trabalho docente.

E como se já não bastasse, soma-se a isso, as influências do Movimento Escola sem Partido em todos os níveis da educação básica, que consiste em uma proposta de privatização ideológica ${ }^{22}$, já que advoga a ausência de discussões de cunho sociopolítico e cultural nos espaços escolares, ao mesmo tempo em que pretende formar massa desprovida de capacidade crítica, analítica e reflexiva.

Segundo Guilherme e Picoli (2018), o Movimento tem tentado aprovar lei própria já há algum tempo. No Senado, o Projeto de lei (PL n. 193/2016) buscava incluir seus ideais na LDB (Lei 9394/96). Antes disso, na Câmara Federal, já haviam sido apresentados dois projetos de lei também respaldos pelo ideário do movimento (PL n. 7180/2014 e PL n. 867/2015). Ao mesmo tempo projetos semelhantes foram apresentados em diversos estados e municípios da

\footnotetext{
${ }^{22}$ Uma vez que o Movimento Escola sem Partido defende que não haja discussões de cunho político no ambiente escolar, ele pretende que uma única ideologia, pretensamente neutra, esteja presente nesses espaços. Assim, usamos a expressão "privatização ideológica" para indicar a apropriação do currículo escolar por determinados grupos, que pretendem impor que unicamente sua filosofia e seus valores políticos, sociais e religiosos possam ser aceitos nos espaços públicos de educação.
} 
federação. Em sua essência, o movimento, criado por representantes de partidos de direita e de movimentos conservadores, intenta coibir qualquer tentativa de formação baseada na perspectiva cidadã, coadunando, com ideais do mercado neoliberal, em seus anseios de formar o trabalhador "competente", consumidor ativo e indivíduo passivo, alheio às questões políticas, sociais e culturais.

Ainda tratando do Movimento Escola sem Partido, afirmamos que ele não consiste em um movimento anti-partido e sim, contra perspectivas políticas de cariz crítico. Segundo Guilherme e Picoli (2018, p. 05), propostas desse tipo "não se limitam a retirar a política em sua dignidade dos espaços escolares e das salas de aulas, mas, ao fazer isso, buscam deliberadamente instituir barreiras para o pleno desenvolvimento da humanidade".

Em entrevista à Revista Veja ${ }^{23}$, em fevereiro de 2019, o ministro da educação, Ricardo Vélez Rodriguez, afirmou ser favorável ao Movimento Escola Sem Partido e à responsabilização dos professores que trabalharem numa perspectiva crítica em sala de aula, alegando necessidade de combate à ideologização precoce das crianças. Nessa mesma entrevista, o ministro manifestou-se favoravelmente à cobrança de mensalidades pelas universidades públicas e, em outra ocasião, afirmou que a "ideia de universidade para todos não existe"24.

Em suma, percebemos que os mecanismos atuais de desresponsabilização estatal pela educação são diversos e operam de diferentes maneiras, envolvendo uma gama de interesses de camadas privilegiadas, que forjou lutas ao longo da história brasileira, em favor da não instauração e/ou do desmonte da educação pública, gratuita e laica. Consideramos que uma das vias de luta seja o enfrentamento tanto nas esferas públicas, quantos nos espaços sociais, por meio da análise, da proposição, da busca de caminhos alternativos por uma educação e sociedade baseadas na cidadania crítica.

\section{A privatização pela omissão: a ocupação do vácuo deixado pelo poder público por instituições privadas}

Trata-se do favorecimento ao mercado de instituições privadas pela omissão dos governos em ofertar educação em quantidade e de qualidade para todos (DAVIES, 2009).

Por serem, de maneira geral, consideradas de melhor qualidade, as escolas privadas são frequentadas pela maioria daqueles que podem pagá-la. No entanto, mesmo entre famílias de baixa renda, há quem lute para manter seus filhos nesse tipo de escola, na esperança de que uma educação básica supostamente melhor que a oferecida pela rede pública possa

\footnotetext{
23 https://veja.abril.com.br/revista-veja/faxina-ideologica/

24https://www.valor.com.br/brasil/6088217/ideia-de-universidade-para-todos-nao-existe-diz-ministro-daeducacao
}

ISSN 2526-2882

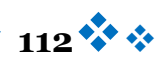


proporcionar condições mais favoráveis no futuro, inclusive permitindo que esses jovens ingressem universidades públicas. No entanto, quanto menor a renda, mais representativo é o peso da educação no orçamento familiar (AKKARI et al., 2011).

Além da qualidade, a escassez de vagas em instituições públicas também contribui para a demanda por instituições privadas. Embora essa relação possa ser um grave problema na educação básica, especialmente em determinadas localidades (DAVIES, 2009), é no ensino superior que as IES privadas vêm preenchendo uma fabulosa lacuna aberta por omissão do poder público.

Uma demanda reprimida por décadas de negligência com a expansão do ensino superior público, as exigências do mercado de trabalho, a acirrada competição por uma vaga em instituições públicas de ensino superior e uma legislação francamente favorável ao mercado educacional (AKKARI et al. 2011) impulsionaram a expansão das redes privadas de ensino superior por todo o país.

Reis e Capelato (2017) informam que atualmente no Brasil mais de 87\% das IES são privadas, que respondem por $75 \%$ de matrículas nesse nível de ensino, impactando diretamente 7,3 milhões de estudantes. Dessa maneira, não é de se estranhar que os negócios educacionais envolvam cifras astronômicas: "com um faturamento expressivo, que totalizou aproximadamente 14 bilhões de dólares, em 2014, a participação apenas do ensino superior privado na economia brasileira, por exemplo, representa 1\% do PIB do país” (REIS; CAPELATO , 2017, p. 26).

De modo que os negócios bilionários ${ }^{25}$ envolvendo grandes conglomerados educacionais demostram bem o tamanho da brecha deixada pela desresponsabilização do Estado no oferecimento de educação pública e gratuita para a população.

\section{A privatização pelo carreamento de recursos públicos para empresas privadas A renúncia fiscal}

Uma vez que o Estado não recebe os impostos referentes à atividade econômica em questão, a renúncia fiscal pode ser caracterizada como uma forma indireta de financiamento de empresas privadas com o uso de recursos públicos. No caso do Brasil, a renúncia é dupla: pela isenção tributária das instituições privadas e pela dedução do imposto de renda pelas famílias. Pinto (2016) lembra que muitos matriculam os filhos na rede privada, levando em consideração o valor deduzido, o que, consequentemente, beneficia, ainda que de forma indireta, essas instituições.

25 https://g1.globo.com/economia/noticia/kroton-fecha-compra-da-somos-educacao-por-r-46-bilhoes.ghtml ISSN 2526-2882

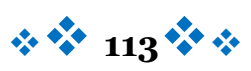


Segundo Davies (2009), desde a Constituição Federal de 1946 as instituições educacionais privadas são isentas de tributos, ressalvada pela Constituição Federal de 1988 a necessidade de não possuírem fins lucrativos. De acordo com Akkari et al. (2011, p. 484), essas instituições declaram-se de utilidade pública não estatais, por não terem caráter lucrativo, buscando assim "se aproximar do status das instituições públicas para poderem ter acesso aos fundos públicos.”.

Assim, escolas confessionais, comunitárias e as filantrópicas oferecem seus serviços ou disponibilizam vagas ao poder público, em troca de isenção de impostos. Pinto (2016) pondera que, embora seja exigido, por lei, que haja contrapartida em troca dos benefícios fiscais, há falhas na fiscalização e por isso, muitas empresas, em vez de ofertarem vagas, criam instituições voltadas ao desenvolvimento de algum projeto comunitário, como por exemplo, "programas de reforço escolar e assistência social para famílias carentes de periferia, cujos filhos estudam na rede pública, o que naturaliza o fosso entre escolas de rico e escolas de pobre e ameniza a consciência sem enfrentar a questão da desigualdade” (p. 147).

As IES com fins lucrativos também podem obter isenção de tributos por meio do Prouni ${ }^{26}$, programa federal que concede bolsas de estudo integrais ou parciais para alunos de cursos de graduação. O Prouni foi instituído pela Lei $n^{0}$ 11.096/2005, em um contexto de defesa pela democratização de acesso e expansão de vagas no ensino superior, constituindo-se em um programa bastante polêmico, pois, se de um lado favorece estudantes de baixa renda, por outro, transfere recursos públicos para a iniciativa privada (PINTO, 2016; ROSA, 2013).

\section{O financiamento direto ao setor privado por meio recursos públicos}

Se a renúncia fiscal pode ser considerada uma forma de financiamento indireto do poder público às instituições privadas, há estratégia mais diretas de transferência de recursos por meio de pagamentos de bolsas, financiamento estudantil etc. Um exemplo é o Fies²7, um programa de financiamento público, a juros subsidiado, para que o estudante possa custear seus estudos em instituições privadas.

Desde o final da década de 1990, vem ocorrendo uma expansão nas matrículas no ensino superior, sendo a velocidade de crescimento do setor privado bem maior que do setor público. Programas governamentais, como o Fies e o Prouni contribuíram para esse aumento, cujo ritmo é afetado pelas oscilações desses programas (ROSA, 2013; REIS; CAPELATO, 2017). Por exemplo, partir de 2010 quando o governo mudou as regras do Fies, diminuindo os juros e aumentando o prazo de carência, "o ensino superior privado passou a vivenciar um novo ciclo

\footnotetext{
${ }^{26}$ http://prouniportal.mec.gov.br/o-programa

27 http://fies.mec.gov.br/
} 
de crescimento", porém, quando a crise de 2015 "fez com que o governo cortasse mais de $70 \%$ das vagas do Fies", houve "graves consequências para a expansão do ensino superior do brasileiro" (REIS; CAPELATO, 2017, p. 28).

Pinto (2016) evidencia que uma das formas de transferência de recursos públicos para o setor privado é o repasse para o Sistema 'S'. De acordo com o autor, é falacioso o discurso propalado pelo setor empresarial de que os recursos do referido sistema são gerados pelas empresas associadas, pois, eles são oriundos de tributos da arrecadação pela Receita Federal do Brasil, "tendo por base essencialmente a folha de pagamentos e, como tributos indiretos que são, têm seu valor repassado ao preço final dos produtos, recaindo o ônus de seu pagamento ao consumidor, e não ao empresário" (p. 137). O estudo realizado pelo autor, demonstra que parte dos recursos são investidos em formação profissional e outra parte para programas de assistência social do trabalhador, porém, não há transparência na prestação de contas e constata-se que o Sistema 'S' tem cobrado pelos cursos oferecidos.

$\mathrm{O}$ autor destaca ainda que o Sistema 'S' tem sido o maior favorecido do Pronatec (Programa Nacional de Acesso ao Ensino Técnico e Emprego). O programa foi criado sob a Lei $\mathrm{n}^{\mathrm{o}}$ 12.513/2011 e tem como finalidade a ampliação de oferta de educação profissional e tecnológica, devendo ser executado, em seus programas, projetos e ações, por meio de parcerias técnica e financeira, com instituições públicas (rede estadual) e privada (Sistema 'S' e instituições privadas de ensino médio e superior ou de educação profissional e técnica em nível médio). Com base em dados referentes aos repasses do programa, ele observa que:

de 2011, ano de início do programa, até maio de 2014 foram repassados 6,5 bilhões ao programa. Desse total, $73 \%$ ao setor privado (ficando o Sistema ' $\mathrm{S}$ ' com $70 \%$ do total de recursos) e $27 \%$ ao sistema público, ficando a rede federal com $20,4 \%$, a rede estadual com $6,3 \%$ e a municipal com $0,3 \%$. Tomando como referência o ano de 2013, os recursos para o sistema privado atingiram $0,04 \%$ do PIB. Cabe comentar que nos termos do art. $5^{\mathrm{o}} \S 4^{\circ}$ da Lei $\mathrm{n}^{\mathrm{o}}$ 13.005/2014 (Plano Nacional de Educação - PNE - 2014-2024) esses recursos devem ser considerados como gastos públicos em educação para efeito do cumprimento da Meta 20 do PNE. Outro aspecto relevante do PNE é que os recursos estão sendo destinados inclusive a instituições privadas lucrativas, o que fere frontalmente $\mathrm{o}$ art. 213 da [Constituição Federal] (PINTO, 2016, p. 139).

Os dados evidenciam que recursos públicos em quantias vultuosas têm sido destinados para a iniciativa privada, quando poderiam ser canalizados para a melhoria ou desenvolvimento de estrutura educacional, a fim de que o poder público pudesse ofertar a educação profissional e técnica.

\section{O terceiro setor}

Um dos casos mais emblemáticos de indefinição entre público e privado é a atuação de ONGs, Fundações e outros tipos de instituições sem fins lucrativos no campo educacional. ISSN 2526-2882

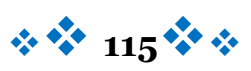


Peroni (2006) analisa a presença dessas instituições privadas na educação pública e na execução de políticas de responsabilidade do Estado, as quais desenvolvem suas ações utilizando recursos públicos. A autora chama a atenção para a dificuldade de avaliação e controle de suas atividades e da prestação de contas a respeito dos recursos utilizados.

Peroni (2018) observa que na Educação Infantil as parcerias público-privadas com instituições sem fins lucrativos são bastante comuns e expressivas no Brasil, porque os municípios (ente federado responsável por esta etapa de educação) não investem na construção de creches e pré-escolas, enxergando nessas parcerias uma forma de economia. A autora ainda destaca que muitas dessas instituições apresentam estrutura e atendimento precários, além de lacunas no projeto e prática pedagógica, gestão, falta de transparência nos critérios na admissão e pagamento dos funcionários, bem como nas relações com a mantenedora, pais e comunidade.

Segundo Pinto (2016), no que tange à educação infantil e educação especial, há a possibilidade de aumento dos convênios entre os municípios e instituições sem fins lucrativos, devido ao baixo custo por aluno repassado pelo Fundeb (Fundo de Desenvolvimento e Manutenção da Educação Básica), bem como à necessidade de cumprimento das metas do PNE (2014-2024). Os municípios são os responsáveis pelos repasses, a fim de que o valor captado do governo federal seja administrado de forma que possibilite ao mesmo tempo, o repasse por aluno, às instituições sem fins lucrativos e ampliação da rede municipal de ensino.

O risco que está por trás dessa opção de atendimento é, no caso da educação infantil, um comprometimento da qualidade, uma vez que os valores repassados geralmente ficam muito abaixo das estimativas feitas, por exemplo, para o Custo Aluno-Qualidade inicial (CAQi), previsto no Parecer $\mathrm{CEB} / \mathrm{CNE} \mathrm{n}^{\circ} 8 / 2010$, e, no caso da educação especial, o risco é desestímulo às políticas inclusivas (PINTO, 2016, p.142).

Outra modalidade de ensino que tem sido alvo de atuação do terceiro setor, é a Educação de Jovens e Adultos, principalmente, por meio do Programa Brasil Alfabetizado. São diversos os exemplos de programas por instituições privadas que desenvolvem ações com financiamento público (PERONI, 2018).

\section{A compra de materiais e serviços}

Adrião et al. (2009) analisaram as relações entre o poder público, especificamente entre prefeituras de pequenos municípios paulistas e empresas privadas, na compra de sistemas de ensino (materiais didáticos para alunos e professores, formação docente, assessoramento etc.). Esses negócios converteram-se em uma "estratégia por meio da qual o setor privado amplia seu mercado, ao incidir sobre o espaço público na mesma medida em que 
o setor público transfere parcela de suas responsabilidades para com a educação à iniciativa privada” (ADRIÃO et al., 2009, 801), com a agravante do frágil controle social sobre os recursos aplicados e as atividades desenvolvidas.

Muitas vezes, os municípios que adquirem algum tipo e material ou serviços de grupos empresariais apresentam baixo Índice de Desenvolvimento Humano Municipal (IDHM), ausência de condições materiais de ensino, etc., mas alocam quantias exorbitantes para grupos fornecedores de pacotes, módulos, capacitação de gestão escolar (ADRIÃO, et al., 2016). Questiona-se a necessidade da compra de sistemas apostilados, já que o MEC disponibiliza materiais didáticos por meio do Programa Nacional do Livro Didático (PNLD). Desse modo, o recurso que poderia ser utilizado para efetivação de medidas mais simples, porém mais plausíveis, necessárias, urgentes e menos custosas, são canalizados para grandes grupos empresariais, sem o retorno devido ou prometido por tais pacotes.

\section{A privatização alardeada como um direito da família: a educação domiciliar}

O ensino doméstico é visto como uma das facetas das reformas educacionais conservadoras (APPLE, 2003, p. 211), posto que lhe é atribuída a função de "preservar as identidades religiosas e transformar tanto a educação quanto o mundo em geral”.

No Brasil, esta modalidade de ensino está em vias de regulamentação e compôs uma das metas dos primeiros 100 dias de governo do atual presidente. O governo enviou documento ao Congresso Nacional solicitando urgência na discussão e apresentou uma Medida Provisória para regulamentar essa modalidade de ensino. Essa ação é resultante, também das reivindicações do Movimento Escola sem Partido, pois, ao defender que os alunos recebam a instrução de acordo com as convicções morais e religiosas dos pais, o movimento fortalece os argumentos para o ensino baseado na formação doméstica ou homeschooling, ao mesmo tempo em que evidencia "a compreensão de que a escola deve limitar sua atuação na instrução e instrumentalização, na transmissão de conhecimentos. Assim, a educação, em seu sentido mais abrangente, diria respeito apenas à família” (GUILHERME; PICOLI, 2018, p.o4).

Apple (2003) afirma que não podemos rechaçar os adeptos do ensino doméstico, mesmo porque o sentimento de aversão à escola é resultante de razões baseadas em critérios ou constatações de "bom senso" e não apenas motivadas por questões religiosas ou convicções ideológicas sem fundamento. No entanto, o autor observa que a grande maioria de adeptos, é motivada por convicções religiosas.

muitos defensores do ensino doméstico são orientados pelo que acreditam ser a compreensão bíblica da família, das relações de gênero, o saber legítimo, a importância da "tradição", o papel do governo e a economia. Embora muitos defensores do ensino doméstico combinem crenças das três tendências que 
identifiquei - neoliberalismo, neoconservadorismo e populismo autoritário é este último que parece impulsionar grande parte do movimento (p. 214).

No Brasil, o ensino doméstico é praticado desde o período imperial, como já assinalamos neste trabalho. Em tempos de outrora, devido à insuficiência de provimento do Estado e atualmente, muito mais por questões ideológicas: políticas, morais e religiosas.

Podemos afirmar que a regulamentação do ensino doméstico, é, de certa forma, um meio de impulsionar a responsabilização dos pais pela educação dos filhos, o que segundo Barbosa (2016), consiste na forma mais radical de privatização, porque promove o crescimento da consciência privada, bem como o individualismo. Apple (2003), ressalta que ideais antiestado ou anti-imposto tem influenciado o movimento pelo ensino doméstico, pois "aqueles que optaram colocar seus filhos em escolas privatizadas, mercantilizadas e domésticas não querem pagar os impostos para sustentar a escolarização do Outro” (p. 231). Nos Estados Unidos, onde o ensino doméstico é legalizado, o governo concede um cheque-ensino para os pais contratarem os profissionais ou para comprarem materiais, porém não há nenhuma prestação de contas publicamente. No Brasil, não temos precisão de como irá ser efetivado.

\section{Considerações}

Atualmente, não é possível discutir a educação sem levar em conta as políticas educacionais voltadas à crescente entrega, pelo Estado, dessa área à iniciativa privada, por meio de acordos, em que o maior beneficiado, é o mercado, ao qual deve subordinar todas as áreas, comportando-se como ente regulador.

Quando analisamos o percurso histórico da educação brasileira, são notáveis as ações de desresponsabilização estatal, as quais resultaram na interferência ou compartilhamento de responsabilidades com diferentes segmentos sociais, sendo que, ultimamente, o mais notável são os grupos empresariais, que têm atuado como principais consultores, planejadores e propositores das políticas educacionais. No entanto, essa participação é imiscuída de interesses, que resultam tanto na expropriação financeira estatal, quanto no engessamento das ações que se concretizam no chão das instituições de educação pública.

Desse modo, os mecanismos de privatização nem sempre são evidentes, pois muitas formas fogem à percepção. Tal realidade denota que o dualismo que coloca, de um lado, as elites e suas instituições educacionais e, de outro, as classes desfavorecidas e a escola pública, precarizada e explorada, tem concorrido para o aprofundamento da desigualdade social. Questões como: currículo, gestão, formação docente, capacitação profissional em serviço, materiais pedagógicos, estrutura escolar, estão sendo cada vez mais mercantilizadas.

Visto que a educação pública, gratuita, laica e de qualidade, atravessa momento de incertezas e crises, devido, entre outros fatores, às constantes mudanças, das quais, muitas são ISSN 2526-2882

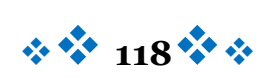


concretizadas de forma célere e impositiva, sem levar em consideração as opiniões, anseios e necessidades dos sujeitos envolvidos e os contextos em que se desenrolam as práticas educativas, resta-nos admitir que é preciso levantar novas frentes de luta, principalmente pelos atores envolvidos no cotidiano das instituições de ensino.

Portanto, cabe-nos, enquanto educadores, nos diferentes espaços de atuação, criar mecanismos que deem base, primeiramente à discussão da realidade apresentada, para então, forjar ações de combate à conjuntura vigente.

\section{Referências}

ADRIÃO, T.; GARCIA, T.; BORGHI, R.; ARELARO, L. Uma modalidade peculiar de privatização da educação pública: a aquisição de "sistemas de ensino" por municípios paulistas. Educ. Soc., Campinas, vol. 30, n. 108, p. 799-818, out. 2009. Disponível em: http://www.scielo.br/pdf/es/v30n108/a0930108.pdf. Acesso em 20 fevereiro de 2019.

ADRIÃO, T. GARCIA, T. O. G.; BORGHI, R.F. BERTAGNA, R. H. PAIVA, G. B.; XIMENES, D. B. Grupos empresariais na educação básica pública brasileira: limites à efetivação do direito à educação. Educ. Soc., Campinas, v. 37, nº . 134, p.113-131, jan.-mar., 2016. Disponível em: http://www.scielo.br/pdf/es/v37n134/1678-4626-es-37-134o0113.pdf. Acesso em 20 de fevereiro de 2019.

AKKARI, A.; POMPEU, C.; COSTA, A. S. F., MESQUIDA, P. Construção histórica de um sistema dual de ensino e indefinição de fronteiras das redes pública e privada no Brasil. Rev. Diálogo Educ., Curitiba, v. 11, n. 33, p. 471-496, maio/ago. 2011. Disponível em: https://www.redalyc.org/articulo.oa?id=189119299011. Acesso em 20 de fevereiro de 2019.

APPLE, M. W. Educando à Direita: mercados, padrões, Deus e desigualdade. São paulo: Cortez, Instituto Paulo Freire, 2003.

AMARAL, N. C. Com a PEC 241/55 (EC 95) haverá prioridade para cumprir as metas do PNE (2014-2024)? Revista Brasileira de Educação v. 22 n. 71, 2017. Disponível em: http://www.scielo.br/scielo.php?script=sci_arttext\&pid=S141324782017000400200\&lng=pt\&tlng=pt. Acesso em: 10 de fevereiro de 2019.

BRASIL. Lei de Diretrizes e Bases da Educação Nacional no 9394 de 20 de dezembro de $1996 . \quad$ Disponível http://www2.senado.leg.br/bdsf/bitstream/handle/id/529732/lei_de_diretrizes_e _bases_1ed.pdf Acesso em: 21 de fevereiro de 2019. 
Emenda Constitucional no 95 de 15 de dezembro de 2016. Disponível em: http://www.planalto.gov.br/ccivil_03/Constituicao/Emendas/Emc/emc95.htm 95/ 15 de dez 2016. Acesso em: 10 de fevereiro de 2019.

. Lei no 13.415/2017, de 16 de fevereiro de 2017- Lei da Reforma do Ensino Médio. Disponível em: http://www.planalto.gov.br/ccivil_03/_Ato20152018/2017/Lei/L13415.htm. Acesso em: 10 de fevereiro de 2019.

- Lei no 13.429 de 31 de março de 2017. Disponível em: http://www.planalto.gov.br/ccivil_03/_Ato2015-2018/2017/Lei/L13429.htm.

Acesso em: 10 de fevereiro de 2019.

Resolução no 3 , de 21 de novembro de 2018, que atualiza as Diretrizes Curriculares Nacionais para o Ensino Médio. Disponível em: http://portal.mec.gov.br/docman/novembro-2018-pdf/102481-rceboo3-18/file. Acesso em: 15 de fevereiro de 2019.

BALL, S.; YODELL, D. Privatización encubierta en la educación pública, Internacional de la Educación. Bruselas, 2007. Disponível em: https://www.joanmayans.com/privatizacion_encubierta_de_la_educacion_publica .pdf. Acesso em 06 de fevereiro de 2019.

BASSI, C. M. Implicações dos novos regimes fiscais no financiamento da educação pública. Ipea, Brasília, 2018. Disponível em: http://www.ipea.gov.br/portal/index.php?option=com_content\&view=article\&id=3 4091\&Itemid=433. Acesso em 09 de fevereiro de 2019.

BARBOSA, L. M. R. Homeschooling no Brasil: Ampliação do direito à Educação ou via de privatização? Educ. Soc., Campinas, v. 37, nº. 134, p.153-168, jan.-mar., 2016. Disponível em: http://www.scielo.br/scielo.php?pid=So101$73302016000100153 \&$ script=sci_abstract\&tlng=pt. Acesso em 10 de fevereiro de 2019.

BELFIELD, C.; LEVIN, H. A privatização da educação: causas e implicações. Edições ASA, 2004.

BIONDI. A. O Brasil Privatizado: um balanço do desmonte do Estado. São Paulo: Fundação Perseu Abramo, 1999.

CHAPANI, D. T. Políticas de formação de professores: o Brasil no contexto da globalização. Góndola, Enseñanza y Aprendizaje de las Ciencias, v. 9, n.1, p. 47-53, enerojunio de 2014. Disponível em https://revistas.udistrital.edu.co/ojs/index.php/GDLA/article/view/7311/9146. Acessado em 20 fevereiro de 2019. 
CUNHA, L. A. Educação, Estado e democracia no Brasil. São Paulo: Cortez. Niterói: Editora da Universidade Federal Fluminense. Brasília: FLACSO do Brasil, 2001.

CURY, C. R. J. O público e o privado na história da educação brasileira: concepções e práticas educativas. In: LOMBARDI, J.C.; JACONELI, M.R.M.; SILVA. T.M. (Org.). O público e o privado na história da educação brasileira: concepções e práticas educativas. Campinas: Autores Associados, 2005.

DAVIES, E. Privatização por omissão: a participação das redes estadual e municipais de educação básica no Rio de Janeiro em 2006 na comparação com as redes privadas. Revista HISTEDBR, Campinas, n. 33, 2009.

DOURADO, L. F.; BUENO, M. S. S. O público e o privado na educação. In: WITTMANN, L. C.; GRACINDO, R. V. Políticas e gestão da educação (1991-1997). Brasília : MEC/Inep/Comped, 2001.

FERRETI, C. J.; SILVA, M. R. Reforma do Ensino Médio no contexto da Medida Provisória no 746/2016: Estado, currículo e disputas por hegemonia. Educ. Soc., Campinas, v. 38, $\mathrm{n}^{\mathrm{o}}$. 139, p.385-404, abr.-jun., 2017. Disponível em: http://www.scielo.br/pdf/es/v38n139/1678-4626-es-38-139-00385.pdf. Acesso em: 11 de fevereiro de 2019.

GUILHERME, A. A.; PICOLI, B. A. Escola sem Partido - elementos totalitários em uma democracia moderna: uma reflexão a partir de Arendt. Revista Brasileira de Educação v. $23, \quad$ p. $\quad 01-23, \quad 2018 . \quad$ Disponível em: http://www.scielo.br/pdf/rbedu/v23/1809-449X-rbedu-23-e230042.pdf. Acesso em 11 de fevereiro de 2019.

JUNQUILHO, G. S. Nem "burocrata" nem "orgânico": o gerente "caboclo" e os desafios do Plano Diretor de Reforma do Estado no Brasil do Real. In: ENCONTRO DE ESTUDOS ORGANIZACIONAIS, 2., 2002, Recife. Anais... Recife: Observatório da Realidade Organizacional: PROPAD/UFPE : ANPAD, 2002. 1 CD.

LIBÂNEO, J. C.; OLIVEIRA, J. F.; TOSCHI, M. S. Educação Escolar: políticas, estrutura e organização. São Paulo: Cortez, 2003.

MORAES, R. C. C. Globalização e políticas públicas: vida, paixão e morte do Estado nacional? Educação e Sociedade, Campinas, vol. 25, n. 87, p. 309-333, mai.-ago. 2004.

PERONI, V. M. V. Conexões entre o público e o privado no financiamento e gestão da escola pública. EccoS: Revista Científica, São Paulo, v. 8., n. 1, p. 11-132, jan.-jun. 2006. Múltiplas formas de materialização do privado na educação básica pública no Brasil: sujeitos e conteúdo da proposta. Currículo sem Fronteiras, v. 18, n. 1, p. 212-238, jan./abr. 2018. 
PERONI, V. M. V.; CAETANO, M. R. Redefinições no papel do Estado: Terceira-via, novo desenvolvimento e as parcerias público-privadas na educação. Revista da FAEEBA - Educação e Contemporaneidade, Salvador, v. 21, n. 38, p. 57-67, jul./dez. 2012.

. O público e o privado na educação- Projetos em disputa?

Revista Retratos da Escola, Brasília, v. 9, n. 17, p. 337-352, jul./dez. 2015. Disponível em: http//www.esforce.org.br. Acesso em 21 de fevereiro de 2019.

PERONI, V. M. CAETANO, M. R; LIMA, P. Reformas educacionais de hoje. As implicações para a democracia. Revista Retratos da Escola, Brasília, v. 11, n. 21, p. 415-432, jul./dez. $2017 . \quad$ Disponível em: http://retratosdaescola.emnuvens.com.br/rde/article/view/793/pdf. Acesso em: 24 de fevereiro de 2019.

PINTO. J. M. R. Uma análise da destinação dos recursos públicos, direta ou indiretamente, ao setor privado de ensino no Brasil. Educ. Soc., Campinas, v. 37, nº . 134, p.133-152, jan.-mar., 2016.

ROSA, C. M. Políticas públicas para a educação superior no governo Lula. Poíesis Pedagógica, Catalão-GO, v.11, n.1, p. 168-188, jan/jun. 2013.

REIS, F.; CAPELATO, R. A relevância do ensino superior privado no Brasil. ESAL - Revista de Educación Superior en América Latina, v. 1., n. 1, p, 26-29, enero-junio, 2017. Disponível http://rcientificas.uninorte.edu.co/index.php/esal/article/viewFile/9430/9074. Acesso em 27 de fevereiro de 2019.

STEIN, et al. A política das políticas públicas: Progresso econômico e social na América Latina- Relatório 2006. Banco Interamericano de Desenvolvimento e David Rockefeller Center for Latin America Studies, Harvard University. Tradução Banco Interamericano de Desenvolvimento, Rio de Janeiro: Elsevier, Whashington, DC: BID, 2007.

SHIROMA, E.O; MORAES, M. C; EVANGELISTA, O. Política educacional. Rio de Janeiro: DP\&A, 2002.

VIEIRA, F. S.; SANTOS, I. S.; OCKÉ-REIS, C. RODRIGUES, P. H. A. Políticas sociais e austeridade fiscal: como as políticas sociais são afetadas pelo austericídio da agenda neoliberal no Brasil e no mundo. Rio de Janeiro, CEBES, 2018.

XAVIER, L. N. Oscilações do público e do privado na história da educação brasileira. Revista Brasileira de História da Educação ${ }^{\circ}$ 5, jan./jun. 2003. 


\section{Biografia Resumida}

Ana Lúcia Santos Souza: Licenciada em Pedagogia pela Universidade Estadual do Sudoeste da Bahia - UESB, campus de Jequié/BA; Especialista em Metodologia do Ensino Superior UESB; Especialista em Psicopedagogia Institucional - Faculdade do Noroeste de Minas- FINOM; Mestra em Educação em Ciências e Matemática- UESB, campus de Jequié; Professora efetiva da Universidade Estadual do Sudoeste da Bahia - UESB, campus de Itapetinga/BA. Integrante do Núcleo de Estudos, Pesquisa e Extensão sobre Educação, Formação Docente, Infância, Leitura e Ludicidade (NEPEFILL), UESB, campus de Jequié/BA.

e-mail: ubatense@yahoo.com.br

Lattes: http://lattes.cnpq.br/8885834935916308

Daisi Teresinha Chapani. Licenciada em Ciências com Habilitação em Biologia. Doutora em Educação para Ciências pela UNESP. Professora Titular aposentada pela UESB. Docente vinculada ao Programa de Pós-graduação em Educação Científica e Formação de Professores.

e-Mail: dt.chapani@gmail.com

Lattes: http://lattes.cnpq.br/8579308623463839 